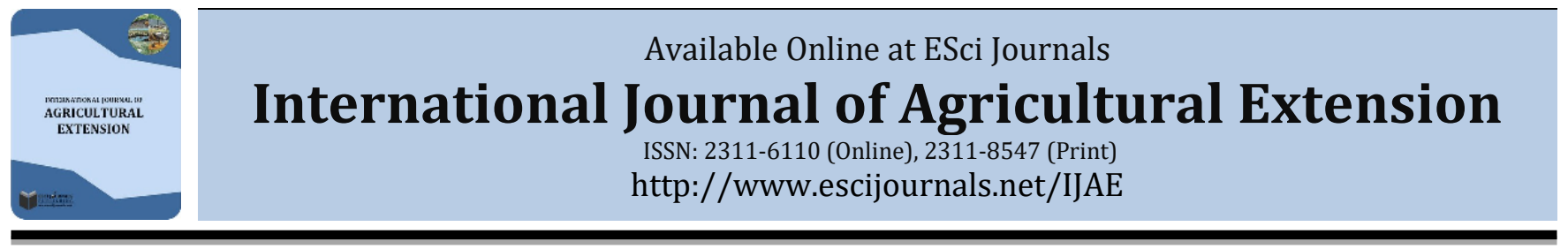

\title{
LIVELIHOOD DIVERSIFICATION AND ITS IMPACT ON COCOA PRODUCTION IN MOROBE AND EAST NEW BRITAIN PROVINCES OF PAPUA NEW GUINEA
}

\author{
William Kerua \\ Department of Agriculture, Papua New Guinea University of Technology, PMB, Lae, Morobe Province, Papua New Guinea.
}

A B S T R A C T

Cocoa is an important cash crop of Papua New Guinea (PNG). Despite considerable Government investment, with its technical research, development, and extension (RD\&E) focus, productivity remains less than potential. This study was carried out to establish the livelihood activities diversification and impact on cocoa production of selected areas of Morobe and East New Britain Provinces of PNG. The specific objective was to establish whether farmers' livelihood diversification activities affected cocoa production of the study areas. A cross-sectional descriptive study, in the context of phenomenological reflection involving semi-structured interviews and discussions was used to study the livelihood diversity and its implications on cocoa production in the selected provinces. Data were analysed using NVivo software. It was found that the main causes of farmer engagement of diversified livelihood activities were due to: land shortage, land tenure, minimising risk, cultural factors, farming system practices, opportunities, comparative advantage, and with the effects of modern changes. The main rationale behind such diversified livelihood activities was to raise household's income portfolio and to improved status in the community. Consequently, smallholder farmers do not put full effort into cocoa production.

Keywords: Livelihood, diversification, livelihood strategy, cocoa.

\section{INTRODUCTION}

Livelihood diversification refers to attempts by individuals and households to find new and multiple ways to raise incomes and reduce environmental risks (Sekumade \& Osundare, 2014). According to the Ellis (2000a) livelihood diversification is a process by which rural households construct a diverse portfolio of activities and social support capabilities in their struggle for survival and improvement in their standards of living. In process of livelihood diversification farmers and households design a range of activities and social support means for survival, recognition, raising income, and adverse to risk. Therefore, livelihood strategies are a range and combination of activities and choices that the households make or undertake to achieve their livelihood goals. In this study, livelihood strategies can be classified into farming and non/off farming and discusses the context and its importance to farmers'

* Corresponding Author:

Email: wkerua69@gmail.com

(C) 2019 ESci Journals Publishing. All rights reserved. livelihood in the study areas and the causes and effects of livelihood diversification on cocoa production. In Papua New Guinea (PNG), cocoa is one of the most important cash crops which is exported to support economy (Bourke \& Harwood, 2009). More than one million farmers in PNG rely on cocoa farming as their main source of income for their fundamental livelihood needs (Omuru et al., 2001). In spite of the importance of cocoa crop to $\mathrm{PNG}$, productivity levels stay impressively lower than the potential (Curry et al., 2007; Lummani, 2008). Various factors affecting cocoa production as identified by various research studies are such as lowlevel farm management, low cocoa selling price, land shortage and labour shortage (Curry et al., 2007; Daniel \& Guest, 2011; Ghodake et al., 1995; Omuru et al., 2001). Hence, the Government, research institutions, extension agencies, cocoa industry, and private sectors have invested in the industry to minimise the constraints, thus, to increase yield over the years but cocoa production remains low (Omuru, 2001b). A recent study by Kerua \& Glyde (2016) established that research, 
development, and extension (RD\&E) were mainly tailored to technical, economical and management aspect of cocoa to increase production but with less attention in considering the socio-cultural aspects of the cocoa farmers livelihoods in planning RD\&E. Although farming is the mainstay of all the farming families of the study sites, it was apparent that rural people no longer remained confined to farming (including cocoa) but combine a range of non-farming activities to construct a diverse portfolio of activities (Kerua \& Glyde, 2016). Ellis (2000a) further stated that livelihood diversification is caused by; seasonality, risk, labour markets, credit markets, asset strategies, and coping strategies. However, no known studies were conducted in PNG to establish the cause and effects of household's diversification of livelihood activities and especially its impact on agricultural production particular about cocoa, hence, this study intend to do that.

Purpose and Objectives: The purpose of this study was to identify livelihood activities farmers' engaged in and to established why they undertake these activities and its impact on cocoa production in the selected study sites of the province of Morobe and East New Britain (ENB). Three objectives guided this investigation: (a) identify various livelihood activities; (b) establish the causes of diversifying into such activities; and, (c) establish the effect of livelihood diversification on cocoa production in the study areas.

The outcome of the study may provide an understanding of major issues and/or opportunities that trigger the households to undertake multiple activities, thus, affecting cocoa production.

\section{METHODS}

A cross-sectional descriptive study, in the context of phenomenological reflection in which qualitative methodology was employed in data collection and analysis. A descriptive qualitative study seeks to provide an accurate description of observations of a phenomenon and is cross-sectional (Kumar, 2014) as the data were collected once, within four weeks. The study adapted the phenomenological approach as it attempts to capture information from people's (farmer's) experience through descriptive analysis (Van Manen, 1990).The approach of this study was based from the problem tree framework as it provides an overview of possible factors affecting livelihood diversification to low cocoa production as an identified problem (see Figure 1).

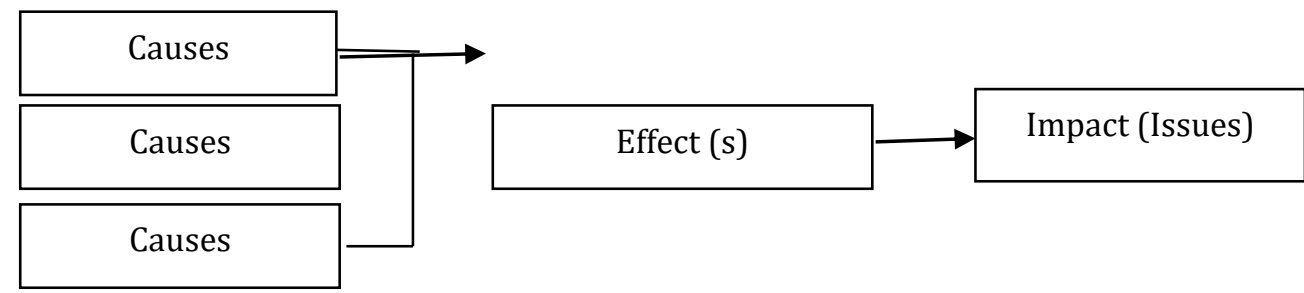

Figure 1. A problem tree framework adopted in establishing cause and effect of livelihood diversification.

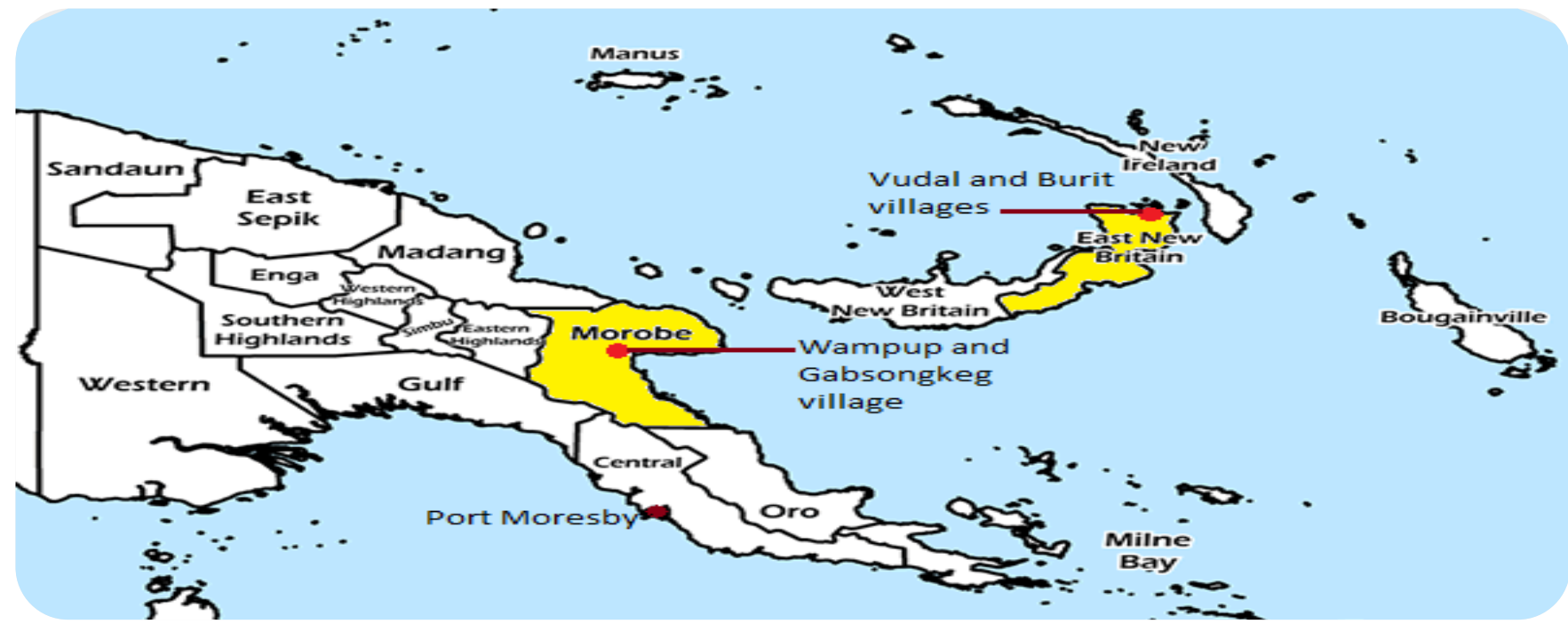

Figure 2. Map of Papua New Guinea indicating the study location (Morobe and East New Britain Provinces). 
This study was conducted in Vudal and Burit villages of ENB Province and Wampup and Gabsonkeg villages of Morobe Province (see Figure 2). The natives of Vudal and Burit area are referred to as the 'Tolai' while the natives of Wampup and Gabsongkeg villages are referred to as 'Wampar'. Since the study was undertaken from an inductive perspective, multiple sources of evidence were drawn on including farmers and extension agents of the Government and cocoa industry in both provinces. Data were collected through in-depth semi-structured interviews supported by the use of probing techniques, and with supportive sources such as direct observations and community-based discussions. Twenty-one smallholder farmers were interviewed of which two were females. A further three extension officers were interviewed as well. Justification of such a sampling population was only established after reaching a saturation point, meaning the number of participants was based on the point where no new information emerged, consistent with the notion of theoretical saturation as derived from Glaser \& Strauss (1967). Given the nature of this study the purposeful sampling method was used to interview selected key stakeholders within the cocoa industry from all levels including farmers and extension agents.

\section{RESULTS AND DISCUSSION}

Is farming the only livelihood strategy? Farming is an important and mainstay of the population of the study areas, however, it was not the only activity to support livelihood. The household economy increase in population, and cultural pressure have affected the Tolai and Wampar households to engage and participate in off/non-farming activities to obtain additional income apart from farming. Participation in these activities plays an important role in increasing household income and strengthening their capacity to meet their needs. The other factor of up taking such strategies was to minimise adverse risks. It was apparent that the experience of the incursion of cocoa pod borer (CPB) and its impact on the cocoa farmers of East New Britain Province (ENBP) (including Vudal and Burit villages) in 2006 have changed the farmers' perspective of how such adverse risks can affect their livelihood (Kerua \& Glyde, 2016). One of the farmers said:

" $C P B$ emerged and destroyed our entire cocoa crop and people went into other activities to earn income but now some of them are back into it [cocoa] again".
The farmers of Wampup and Gabsongkeg have experienced the same when palm weevils destroyed their betel nut trees in 2002 (Kerua \& Glyde 2016). Such experience had strengthened the farmers' choices of diversifying into other non/off farming strategies such as handcrafts, fishing (Vudal villagers), PMV business, trade store business, saw milling, seeking employment, growing fresh produce for market, and so on to obtain additional income apart from farming cocoa. Participation in these activities plays an important role in increasing household income and strengthening their capacity to meet their needs. A farmer said:

"Yes, I delegated the cocoa farm to my wife and children with some helpers to take care of it while I concentrated on sawmilling. I also run a PMV (public transport) business as there is good money."

Farmers equally value their cultural practices and obligations that define their status in the community; therefore, equal time and resources or even more are invested in such. Farmers and their families also have their gender responsibilities for the upkeep and the providence of the household and so utilise their scare resources further into such circumstances. They find a balance from work to have leisure time for relaxation and to embrace their relationship with wantoks (relatives). Such multiple activities should not be seen as to maximise profit (income), but it demonstrates that the farmers seek to make a reasonable income for a reasonable amount of activities with fewer risks for their survival and to embrace their culture, customs and traditions, and that is their way of life.

Possible cause and effects of livelihood diversification on cocoa production: The farmers and households of the study sites have diverse livelihood strategies for survival and various purposes as discussed above. However, what has caused farmers to diversify their livelihood activities, and are there any implications on cocoa production? Studies in other developing countries (Carney, 1999; Chambers \& Conway, 1992; DFID, 1999; Ellis, 2000b) indicate that a diverse portfolio of activities contributes to the sustainability of a rural livelihood because it improves its long-run resilience in the face of adverse trends or sudden shocks. They claimed that livelihood diversification is caused by seasonality, risk, labour markets, credit markets, asset strategies, and coping strategies. ; However, based on 
the findings of this study, it was apparent that livelihood diversification was caused by; land shortage, land tenure, minimising risk, cultural factors, farming system practiced, opportunities, comparative advantage or farmers' convenience, and the modern changes as illustrated in Figure 3. Due, to such triggering factors, the farmers and household diversity into multiple activities at any one time and not only on cocoa production.

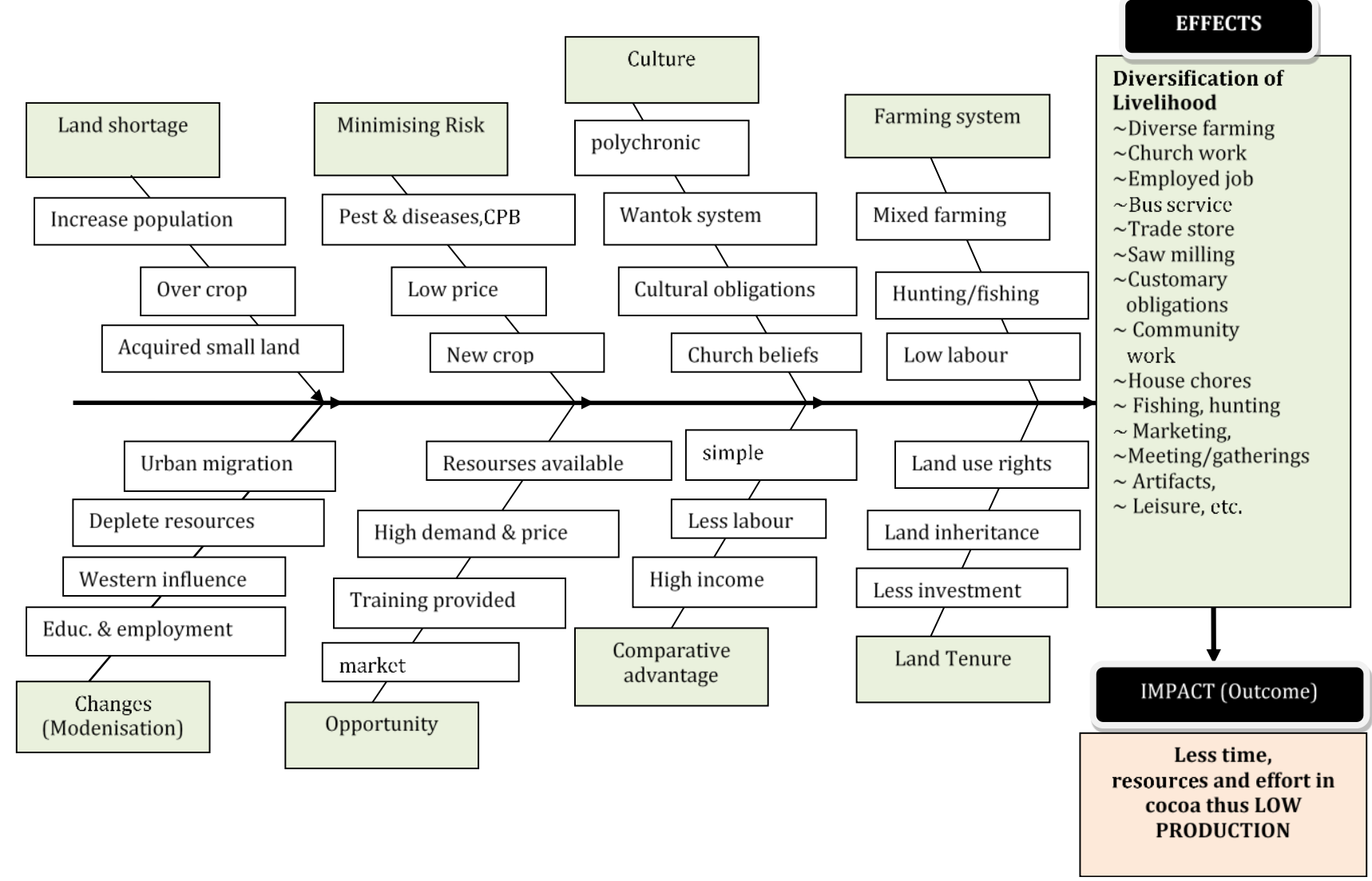

Figure 3. Illustration of cause and effects of various activities in livelihood and its impact on cocoa production. (Source: Author).

According to this study, the factors identified in Figure 3 are the contributing factors to livelihood diversification in the study areas, thus contemplated to have affected the cocoa production.

Land tenure: Livelihood of people in all study areas revolves around their land and so land becomes paramount part of their life. All individuals in the village have access to land to farm their crops and animals but may not necessarily own the land. Land ownership is tied to the land tenure system in each society.

There has been a wide debate on land tenure security and agricultural productivity and investment. Several literature suggests that secure land rights such as individual rights to purchase land is likely to raise investment, and induce greater motivation on the owner (Besley, 1995; Myyra et al., 2007). There is lack of empirical evidential support to justify the link between land tenure security and agricultural productivity. The tendency of connecting land tenure to affect agricultural productivity is, however, intriguing. Therefore, from the findings of this study and from a phenomenological essence of analogy we can allude that insecurity of land tenure was a vital factor that affected productivity of cocoa and other key investment by farmers. The reason for reaching to this affirmation is ascribed in the example of a matrilineal land tenure system practiced by the Tolai people and communal or family owned lands as about Wampar people.

Firstly, Vudal and Burit (Tolai) community of ENBP belong to matrilineal society and so women inherit the land and make decisions over the customary land (unless purchased).

Given such circumstances men were reluctant to invest or developed the customary land as they were aware of 
the implication very well that in an event, they are deceased or encounter land disputes, their sisters will have rights over the land and not their children. For example, a Tolai farmer stated:

If I want to plant more cocoa or do something on the customary land I would think twice that it won't be my children who will benefit, but it would be my niece and nephews according to Tolai customs where women inherit land and not men'.

Most male farmers from Tolai apparently have deviated to short-term land use strategies rather than long-term investment on the land, such as expansion of cocoa trees, replanting, or application of improved cocoa management techniques that requires considerable efforts. ; Therefore, matrilineal land tenure system was found to be a discouraging factor for Tolai male farmers to fully committing resources into cocoa but into other livelihood activities, unless the land was purchased and owned by men. But, the Wampup and Gabsongkeg of Morobe Province people practice agnatic kinship; however, few family members or the clan (communal land) owns the land. ; Thus, most farmers are merely custodians of the land and do not have legitimate rights over intense land use as they are mindful of the consequences. ; Accordingly, the farmers ascribe to short-term strategies such as growing vegetables for market than long-term investment and productivity like cocoa farming.

Despite the different land tenure lineage practiced by the Tolai and Wampar farmers the effect of the land tenure system and ownership had similar impact on farmers in both regions, where they were discouraged to commit long-term investment on the land as they feel that they do not have legitimate ownership but merely custodians of their acquired land. ; Therefore, it is indisputable that, land customary tenure system is seen to be a contributing factor that affects farmers' decisionmaking in the utilisation of assets and choice of activities to other livelihood activities that would have direct benefit to them than long-term investment in cocoa.

Land Shortage: Farmers of Vudal and Burit own farming land of less than two (2) hectares and 50 percent of the land is planted with cocoa and the remaining is used for food gardening, housing and other uses.

Population in these villages have also increased where extended families are living in one farm block, which puts pressure on land use, therefore, there is no extra land to expand on cocoa or to do other farming activities. A farmer explained;

'Cocoa is here to stay, but we must have more land to grow cocoa, otherwise, land shortage is a problem'.

Farmers and their families are pressured into doing other non and/or off farming activities such as trade store or bus service business, fishing (Vudal farmers), causal employment and so on.

Farming System: Farming is a dominant livelihood activity of the Tolai and Wampar people. Both societies are predominantly a rural-based economy, dominated in the early stages by subsistence agriculture and informal activities, therefore, the rationale for farming is merely for survival. Culturally, farming is their way of life where farmers acquired various traditional methods and techniques of farming and passed these down through the generations. Farmers are wary of variability and risks; therefore, they engage in multiple farming and non-farming activities to provide sustenance for the families for survival. Farmers in all study areas practice mix farming and not specialised in a particular crop. They diverse into various crops mainly for consumption and surplus are sold in local markets with less input of labour and resources. Farmers in both societies do not farm as business. Cocoa was introduced as a cash crop that required intensive farm management practices, proper and adequate use of chemical and fertilizers, and labour inputs. It is a capitalist based approach that is opposed to how the Tolai and Wampar farmers are used to as subsistence based and not profit oriented. The approach of the farmers toward cocoa management is influenced by traditional ways of farming; therefore, cocoa in most cases is not given the treatment it expects for favourable production.

Minimising Risks: Risks also play a key role in the activity diversification process. Based on farmers experiences and instincts encourage households to turn to a more diversified portfolio of activities to minimise risks in income, food, and wellbeing. Both Tolai and Wampar farmers indicated that they are comfortable in doing multiple farming and non-farming activities so they can earn income from various sources then focus on one activity. The Tolai farmers have experienced the cocoa pod borer (CPB) outbreak in 2006 that destroyed all their cocoa trees and because they diversified in to 
other activities, they could survive in terms of income. A Tolai farmer said:

'Cocoa is okay, but after the experience of CPB I am reluctant to concentrate on cocoa again so I am more into food gardening and other activities for food and income'.

Apart, from the CPB experience, some farmers' abandon their cocoa blocks because of low cocoa prices and ventured into other income generating activities such as food crops and chicken as the market prices were good. Wampar farmers experienced similar disaster in 2002 that wiped out their betel nut trees, which was their main source of income. They struggled and diversified into other food crops and cash crops for income as described by a farmer:

'when our betel nut were destroyed by disease people didn't know what to do to support their families... people's moral was down with a lot of pressure and devastated as they had no money to meet their needs. People really suffered, no more happiness, no movement of people, so people started gardening more food crops. Others were looking for alternative cash crops'.

It was also clear in both regions that the households prefer to stick to traditional crops for which risks are known, even though expected returns associated with alternative activities are higher, and a more diversified portfolio of activities would certainly reduce the expected hazard of total income.

Culture: The Tolai and Wampar communities may have some differences in their culture, but the principle of their social network is quite similar and in common such as 'wantok system'. 'Wantok' is a term used in reference to anyone who speaks the same language, comes from the same area, and has common social associations or ethnic background. Through 'wantok' system, within the norm of extended family or the clan, each member can expect basic provisions and sustenance such as housing, food, health care, security, and a general sense of inclusion and belonging, and even money. The reward in return is reciprocated when need arises. People in the community see this as an affirming way for the community to share its resources and are widely accepted. It could be argued that the effect of the 'wantok system' means some villagers put less effort into cocoa production and other income generating activities knowing that their 'wantoks' will provide when the need arises.

Secondly, time is valued and important in many societies globally; however, the Tolai and Wampar people, and the rest of the country do not see time as important and so are polychronic. Time is not an issue to the people, they adjust their activities to available time to suit their needs. Farmers also revealed that they spend a considerable amount of their time on other activities rather than cocoa:

'I spend a lot of time in our Ward doing council work, and I don't spend enough time in cocoa or farming work or with family'.

Farmers also involve in a number of church activities and customary obligations and do not attend to their cocoa blocks.

'I am a farmer, but I think I am spending more time with church work. I am currently helping the carpenters to build our new church because all blessing comes from God and it is rightful to support church work'.

Some farmers focus on activities that would improve their status in the community (social prestige) such as doing church work, village leader, farming more animals such as pigs and cattle (especially the Wampar community). The involvement in such brings recognition by the community.

Comparative advantages: From the observations, farmers in all study areas are smart economists to some extent where they could not continue with a livelihood activity that has some financial risks (low price, high input, poor market, pest \& diseases, etc.). The more tangible benefits of an activity, the more farmers were willing to practice and adopt. This support the Rogers (2003) relative advantage theory where the degree to which an innovation is perceived as better than the current it is intended to replace. Cocoa is grown by all farmers interviewed but, most preferred to do activities that were less labour intensive, high, and fast income within less time and easy to manage. Cocoa is the third most important agricultural export in Papua New Guinea (PNG) with more than one million farmers in the coastal areas of PNG dependent on cocoa farming as their main source of income (Omuru et al., 2001) .Hence, a lot of effort and resources are put into it cocoa but the market 
price is low, so they give less attention to cocoa and focus on other activities as a farmer eluded:

'Cocoa is okay, but requires a lot of work and the price is low, and too after the experience of $C P B$ I am reluctant to concentrate on cocoa again. I am now into sawmilling simply because there is very good income from timber than cocoa'.

It seems that most farmers focus on activities related to economic gains, satisfaction, and convenience associated with it, and simple to manage, than crop like cocoa.

Opportunities: Farmers in all study areas are mindful of any opportunities in income generating activities apart from cocoa. They are responsive to price and availability of markets and back up resources and take on any activities given the opportunity. Training was seen to be another motivating factor that prompts farmers to exercise what they learnt rather than focussing merely on cocoa. The obvious factor that farmers were reluctant to concentrate on cocoa was the cocoa price and risk especially after their experience with the outbreak of CPB.

'Yes, after the experience of CPB I am not too keen in cocoa but look at other food crops that make good quick money like peanut. Peanut is a good crop because we earned a lot of money and you know it's not hard work, we plant, weed, harvest, clean, bundle, and sell. One garden gives me K500'.

Change in livelihood activities (modernisation): It was also noted that a good number of population in the community were employed and work in local town (Kokopo or Lae) and/or in other provinces and remit money back to community. There are trends of urban migration, especially the youths into town and cities and are unable to contribute to any farming activities in the community including cocoa. The line of young generations in all sites are lazy to work the land and resort to drug and home brewed alcohol (illegal) and create disharmony in the community. These influences divert especially the youths away from farming activities, thus, become burden on the parents. This contributes to low labour input to cocoa and other farming activities. A farmer said;

'what I see from young people now, they are into marijuana and home brew.
These two drugs are destroying our young ones and become lazy and can't work in the gardens or help their parents. They cause trouble in the community'.

Such behaviour of the youths was common in all study areas and is a concern to the society. If the trend continues, then it may have negative impact on agriculture production in all sectors of rural agriculture in the future.

\section{CONCLUSION AND RECOMMENDATIONS}

This study has provided an understanding of the causes of livelihood diversification and underlying effects, thus, affecting smallholder cocoa production. Generally, the Tolai and Wampar people had similar reasons for diversifying into various livelihood activities despite some differences in their culture. The study established several possible associated factors that have caused farmers to diverse into other livelihood activities. With the use of problem tree the causes were identified as land shortage, land tenure, minimising risk, cultural factors, farming system practiced, opportunities, comparative advantage, and the effects of modern changes. Best cocoa farming practices with use of high yield clones should be encourage as the crop can produce more beans in small portion of land to address land shortage. Moreover, equal participation of both men and women in cocoa farming should be encourage to alleviate land tenure issues. The diversification of livelihood activities triggers the farmer to distribute the scarce resources (assets) thinly to these activities including cocoa production. Growing cocoa is one of those strategies and not the only activity of the farmer.

Tolai and Wampar farmers are mindful of any opportunities in income generating activities apart from cocoa. They are responsive to price and availability of markets and backup resources, thus, take on any activities given the opportunity such fresh produce, animal farming, sawmilling, and so on. Furthermore, the farmers are very entrenched within their cultural and traditional practices and consider farming more as a way of life to survive and not farming as business. Farmers seem averse to risk, comfortable in diverse livelihood activities, and seek to make a reasonable income rather than focusing solely on cocoa production that required intensive farm management practices, proper and adequate use of chemical and fertilizers, and labour inputs. 
It is apparent that livelihood diversification is seen to be an important factor that contribute to low cocoa production as farmers diversify to other activities and inadequate attention is given to cocoa. It is important to recognise that cocoa growing is part of the farming activity and not the sole crop as farmers equality participate in other crops and non-farming activities. Given such circumstance, the cocoa industry and Government should rethink in its approach to cocoa farmers in facilitating cocoa development in a holistic way then narrowing to cocoa only.

\section{REFERENCES}

Besley, T. (1995). Property Rights and Investment Incentives: Theory and Evidence from Ghana. Journal of Political Economy, 103(5), 903-937.

Bourke, M., \& Harwood, T. (Eds.). (2009). Food and Agriculture in Papua New Guinea. Canberra.: ANU E Press, The Australian National University,.

Carney, D. (1999). Approaches to Sustainable Livelihoods for the Rural Poor. ODI Poverty Briefing.

Chambers, R., \& Conway, G. (1992). Sustainable Livelihoods: Practical Concepts for the 21st Century In IDS Discussion Paper 296. Brighton, UK: Institute of Development Studies.

Curry, G., Koczberski, G., Omuru, E., \& Nailina, R. (2007). Farming or Foraging? Household labour and livelihood strategies amongst smallholder cocoa growers in Papua New Guinea. Perth Black Swan Press.

Daniel, R., \& Guest, D. I. (2011). Enhancing Papua New Guinea smallholder cocoa production through greater adoption of disease control practices. Canberra: Australian Centre for International Agricultural Research.

DFID. (1999). Sustainable Livelihoods Guidline Sheets. Avialible from the livelihoods learning platform. Retrieved 27 Nov, 2012, from www.dfid.liveihoods.gov.uk.org

Ellis, F. (2000a). The Determinants of Rural Livelihood Diversification in Developing Countries. Journal of Agricultural Economics, 51(5), 280-302.

Ellis, F. (2000b). Rural Livelihoods and Diversity in Developing Countries. Oxford: Oxford University Press.
Ghodake, R. D., Cook, K. E., Kurika, L., Ling, G., Moxon, J. E., \& Nevenino, T. (1995). A rapid rural appraisal of the cocoa and coconut farming systems in the Northeast Lowlands of the Gazelle Peninsula of East New Britain Province Technical Report (Vol. 95). Konedobu: Department of Agriculture \& Livestock.

Glaser, B. G., \& Strauss, A. L. (1967). The Discovery of Grounded Theory: Strategies for Qualitative Research New York Aldine.

Kerua, W., \& Glyde, S. (2016). Beyond the cocoa farm: a new look at farmers' choices in livelihood activities and impact on productivity in selected areas of Papua New Guinea. Research, Extension and Innovation Systems Journal, 12 (1).

Kumar, R. (2014) Research Methodology: A Step-by-Step Guide for Beginners, SAGE.

Lummani, J. (2008). Socio-economic considerations in smallholder cocoa production Paper presented at the Cocoa Nutrition Workshop, Tavilo.

Myyra, S., Pietola, K., \& Yli-Halla, M. (2007). Exploring long-term improvements under land tenure insecurity. Agricultural Systems, 92, 63-75.

Omuru, E. (2001b). Understanding the smallholder cocoa and coconut sector in Papua New Guinea. A Review of Cocoa and Coconut Research in PNG (Vol. Occasional Paper 9). Kerevat, East New Britain Province,: PNG/University of New England.

Omuru, E., Nailina, R., \& Fleming, E. (2001). A socioeconomic baseline survey of cocoa and copra smallholders in East New Britain. Occasional Paper, 1.

Rogers, E. (2003). Diffusion of innovation (5th ed.). New York: Free Press.

Sekumade, B., \& Osundare, O. (2014). Determinants and Effect of Livelihood Diversification on Farm Households in Ekiti State, Nigeria. Journal of Economics and Sustainable Development, 5(5), $104-110$.

Summer Institute of Linguistics. (2012). PNG language distribution maps. from http://www01.sil.org/pacific/png/show_maps.asp

Van Manen, M. (1990). Researching lived experience: Human science for an action sensitive pedagogy. London, Ontario: Althouse Press. 